\title{
CAPACITY LIMITS OF BASIC TURBO-ROUNDABOUTS
}

Turbo-roundabouts with their specific design characteristics have become a suitable solution of a single-lane roundabouts capacity problem and a standard two-lane roundabouts safety problem. There is no doubt that turbo-roundabouts ensure a higher level of traffic safety in comparison to standard two-lane roundabouts due to a reduction of both conflict points and driving speed through the turbo-roundabouts. The question is if turbo-roundabouts can provide the same or a higher capacity than standard two-lane roundabouts. The answer, in the form of some important results of the basic turbo-roundabout total capacity at various traffic conditions and also in comparison with standard two-lane roundabouts, is presented in the paper. The capacity model is based on the gap-acceptance theory. Driver behaviour characteristics have been respected according to the Slovak technical guidelines. Redistribution of traffic flows into two lanes at entries and circulatory carriageway of roundabouts has been considered in the capacity calculations. An effective use of both lanes (left and right) has been assumed only at basic turbo-roundabout major entries. By contrast, low use of inner (left) lanes by drivers at entry and circulatory carriageway corresponding with real conditions in some countries has been assumed in the standard two-lane roundabout capacity calculations.

Keywords: Traffic safety, capacity, two-lane roundabout, turbo-roundabout.

\section{Introduction}

A turbo-roundabout is a relatively new type of roundabout. It was developed by the researcher Lambertus Fortuijn from the University of Delft in the Netherlands in 1996 as a solution of a capacity problem of single-lane roundabouts and a traffic safety problem of multi-lane roundabouts. Over the last ten years, turboroundabouts have been successfully implemented, apart from the Netherlands, in many European countries such as Germany, Slovenia, Belgium, the Czech Republic, Poland, Hungary and several others. Currently, over 400 turbo-roundabouts are built in Europe and this number continuously grows.

Foreign experience clearly confirms a higher traffic safety of turbo-roundabouts in comparison to multi-lane roundabouts, however, the question whether turbo-roundabouts can provide the same or higher capacity than multi-lane roundabouts is frequently discussed [1, 2 and 3]. In this article, a comparison of the total capacity of a basic turbo-roundabout and a standard two-lane roundabout (Fig. 1) at different traffic conditions is presented.

\section{Main concept of turbo-roundabout}

A turbo-roundabout is a specific type of multi-lane roundabout with a spiral arrangement of two or more circulating traffic lanes, where drivers are forced to follow a specific path according to their intended destination (Fig. 1, left) [3]. Traffic lanes in the entry, circulatory carriageway and exit zones are physically separated by specially shaped elements, which divert drivers to change traffic lanes in the roundabout [4]. Raised lane dividers are only interrupted at places of entry into the inner traffic lanes of circulatory carriageway.

The new circulating lane formed on the inner side of circulating carriageway of turbo-roundabouts (nested spiral lane) is designed opposite to the major entries (A and B in Fig. 1, left). Major entries are considered in dominant direction of the main traffic flow which is a criterion for selection of a suitable type of a turbo-roundabout (basic, egg, knee, spiral, rotor or star [5]).

The physical separation of traffic lanes and the specific geometry of turbo-roundabouts are the most important features affecting traffic safety and capacity differences in comparison to two-lane roundabouts.

\section{Traffic safety improvements}

In the simplest case, on a standard two-lane roundabout with two-lane entries and two-lane exits, there are 24 conflict points (Fig. 2, right). However, in reality, the traffic situation is much more complicated. Because there is no clearly specified legal framework for passing through the roundabout, drivers can enter the roundabout using any circulating lane, change lane at the

\footnotetext{
* Andrea Kocianova

Department of Highway Engineering, Faculty of Civil Engineering, University of Zilina, Slovakia

E-mail: andrea.kocianova@fstav.uniza.sk
} 

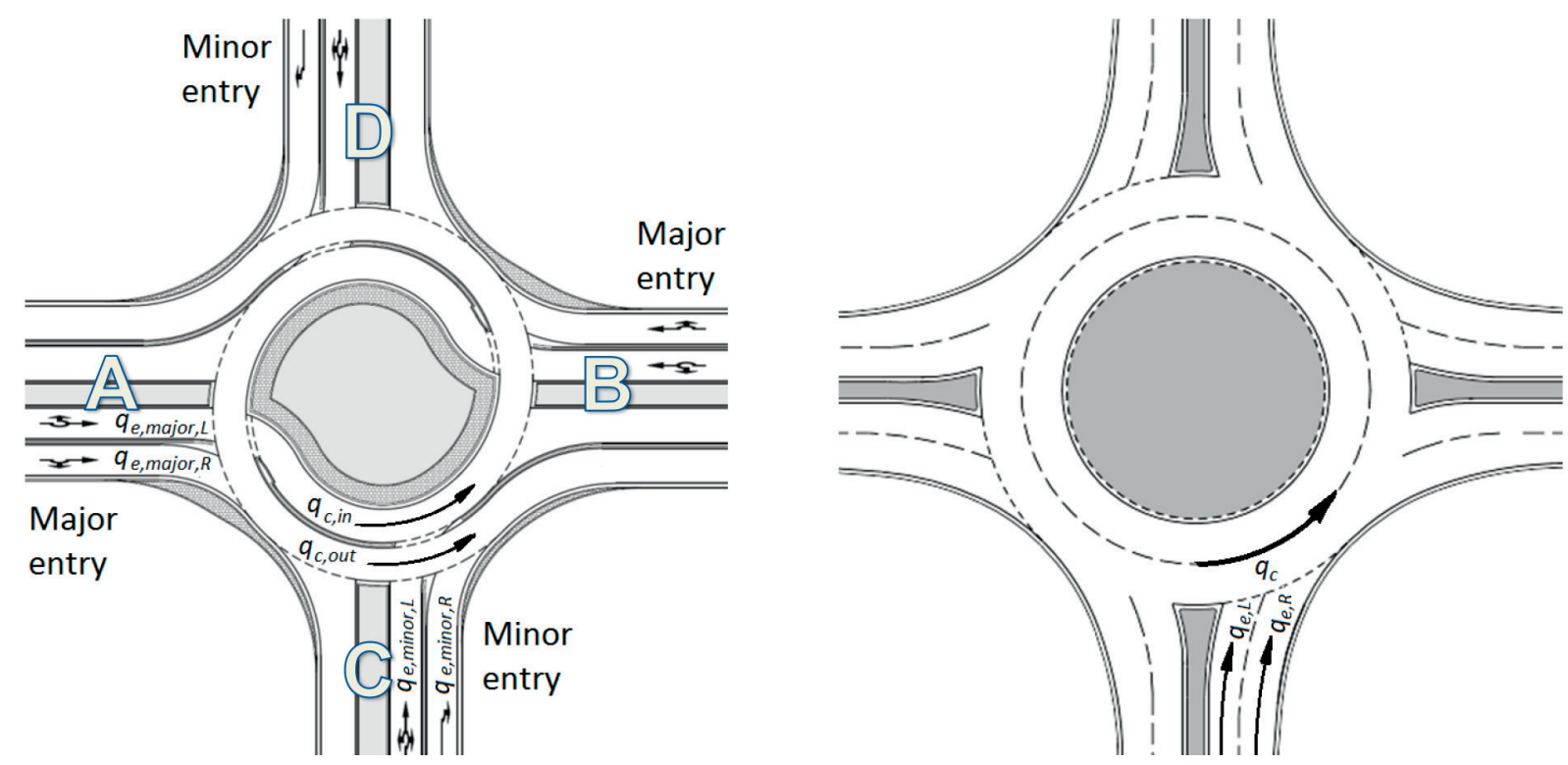

Fig. 1 Geometry of a basic turbo-roundabout (left) and a standard two-lane roundabout (right), Source: Author

circulatory carriageway and also they can leave the roundabout using any exit lane. This driver behaviour results in additional conflict points and weaving conflicts which, together with higher speeds, raise the risk of accidents. International experience has confirmed these functional problems. Accidents in the circulatory carriageway, although not usually serious, are frequent and often affect the normal traffic flow [2].

Traffic safety improvement of turbo-roundabouts in comparison with two-lane roundabouts is ensured thanks to the specific geometry (spiral alignment of circulating traffic lanes leading drivers to the correct exit) and the raised lane dividers. As a result, there are several advantages from the viewpoint of traffic safety: the reduction in conflict points from 24 to 14 (reduction of entry and exit conflict points including the elimination of very dangerous crossing conflict points at the exit from the inner circulating lane, see Fig. 2), the removal of weaving (lane changing) in the circulatory carriageway, the elimination of sideby-side accident risk and the reduction of driving speed through the roundabout. It ultimately means a global reduction of crash probabilities.

Several studies have shown that crash risk is reduced by $70 \%$ when the standard two-lane roundabout is converted into the turbo-roundabout [5]. Other study, based on the analysis of potential conflicts modelled in different layouts and traffic conditions, has shown that turbo-roundabouts provide about $40-50 \%$ reduction of total potential accidents and about $20-30 \%$ reduction of potential accidents with injuries in comparison with two-lane roundabouts [6]. Some studies even concluded that safety of turbo-roundabouts is comparable with the safety of single-lane roundabouts [5].
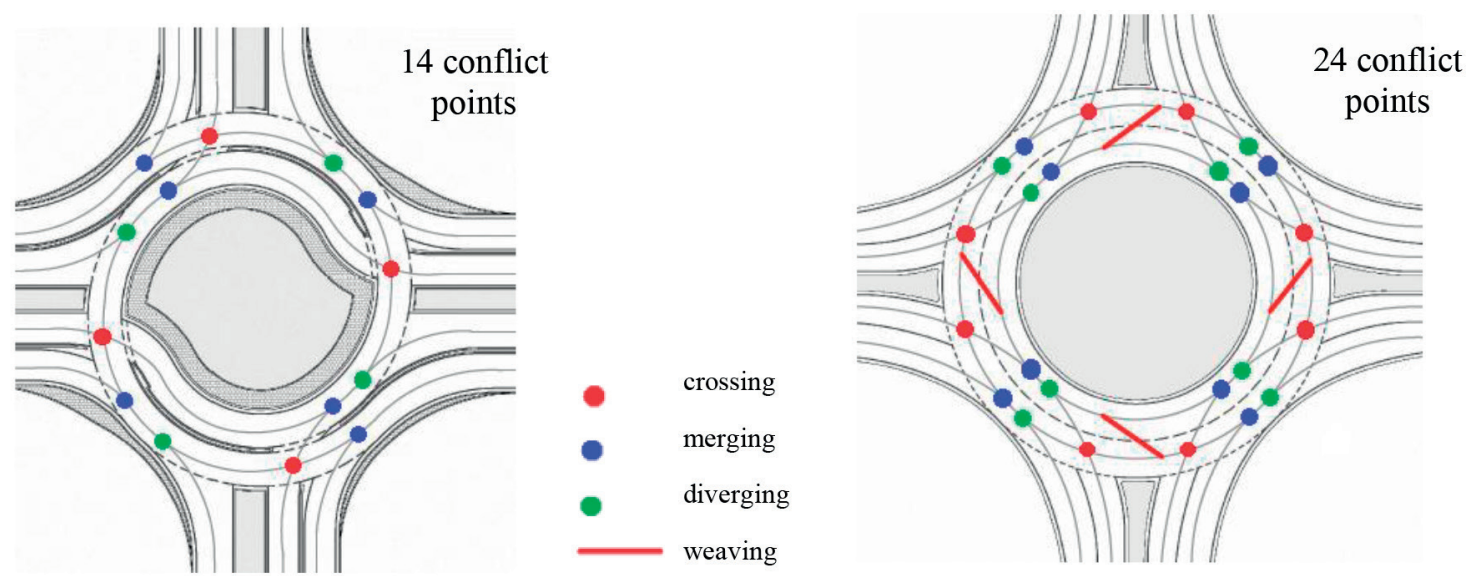

Fig. 2 Conflict points and weaving conflicts on standard two-lane roundabouts (right) and basic turbo-roundabouts (left), Source: author 
In a study based on micro-simulation, it is shown that drivers using the outer circulating lane of turbo-roundabouts drive slower than on two-lane roundabouts. The reduction in the speed is from $48 \mathrm{~km} / \mathrm{h}$ to $38 \mathrm{~km} / \mathrm{h} \mathrm{[7].} \mathrm{One} \mathrm{of} \mathrm{the} \mathrm{factors} \mathrm{affecting} \mathrm{the} \mathrm{speed}$ profile of drivers on turbo-roundabouts is the path curvature (system of inverse radii). The raised lane dividers play also an important role. They "force" drivers to use the predefined trajectory with smaller radii at lower speeds, thus contributing to the homogenous low-speed profiles [2]. On the contrary, drivers on two-lane roundabouts can ignore lane markings and pass the intersection on a shortened trajectory at high speed.

\section{Capacity of turbo-roundabouts}

Turbo-roundabouts have always larger capacity compared to single-lane roundabouts. The reason is turbo-roundabouts have usually two-lane entries, which directly continue into two-lane circulatory carriageway. When comparing capacity of turboroundabouts to standard two-lane roundabouts, it is necessary to take into account the geometry differences between the two kinds of roundabouts affecting the capacity performance at a variety of traffic conditions.

The main geometry differences between compared the basic turbo-roundabout and the standard two-lane roundabout with two lanes at all entries and exits (Fig. 1) are the following:

- A circulating traffic flow in front of the major entries (A and

B) on the turbo-roundabout is concentrated in a single circulating lane, whereas on the two-lane roundabout, there are two circulating lanes available.

- While a through traffic flow can use only a left lane at the minor entries (C and $\mathrm{D}$ ) on the turbo-roundabout, both left and right entry lanes on the two-lane roundabout are available.

- A right-turning traffic flow can use both left and right lanes at the minor entries ( $\mathrm{C}$ and $\mathrm{D}$ ) on the turbo-roundabout, whereas on the two-lane roundabout, only the right lane is used by the right-turning traffic.

- The change of lanes on the circulatory carriageway is not allowed (nor necessary) for drivers on the turbo-roundabout, whereas on the two-lane roundabout it is possible.

The above differences in geometry of roundabouts also affect the traffic redistribution at two-lane major and minor entries, and on two-lane circulatory carriageway. Because it has a significant influence on the entry capacity, it was further considered within the capacity calculations.

\subsection{Capacity model}

Capacity model used in this paper is based on the gap acceptance theory and capacity calculations are lane-based.
Specifically, a formula proposed by Brilon [8] is used for capacity calculation of each entry lane to the basic turbo-roundabout and a formula proposed by $\mathrm{Wu}[9]$ is derived for capacity calculation of each entry lane to the standard two-lane roundabout.

The capacity model used for the basic turbo-roundabout is sensitive to the traffic flow allocation to both inner and outer lane on the two-lane circulatory carriageway. However, it does not take into account an influence of differences in critical headways and follow-up times which have a very low impact on the capacity compared with the traffic flow allocation in the circulating lanes [3].

Left-lane capacity at the minor entries (C and D in Fig. 1) considering the traffic flows in the inner circulating lane $\left(q_{c, i n}\right)$ and in the outer circulating lane $\left(q_{\text {cout }}\right)$ was calculated according to equation:

$$
\begin{aligned}
C_{e}= & \frac{3600}{t_{f}} \cdot\left(1-\frac{t_{\min } \cdot q_{c, o u t}}{3600}\right) \cdot\left(1-\frac{t_{\min } \cdot q_{c, \text { in }}}{3600}\right) . \\
& \cdot e^{-\frac{q_{c, \text { out }}+q_{c, \text { in }}}{3600} \cdot\left(t_{c}-\frac{t_{f}}{2}-t_{\min }\right)}
\end{aligned}
$$

where:

$\mathrm{C}_{\mathrm{e}}$ basic capacity of entry lane $[\mathrm{pcu} / \mathrm{h}]$,

$\mathrm{q}_{\mathrm{c}, \text { out }}$ traffic flow on the outer circulating lane in front of entry $[\mathrm{pcu} / \mathrm{h}$,

$\mathrm{q}_{\text {cin }}$ traffic flow on the inner circulating lane in front of entry $[\mathrm{pcu} / \mathrm{h}$,

$t_{c} \quad$ critical gap [s],

$t_{f}$ follow-up time [s],

$\mathrm{t}_{\min }$ minimum gap between succeeding vehicles on the circulatory carriageway [s].

A considerable impact of the circulating traffic flow allocation in the inner and the outer circulating lanes on the entry lane capacity is shown in Fig. 3. The maximum capacity is achievable at equal distribution of the circulating traffic flow to circulating lanes (the curve 50/50 in Fig. 3) and the minimum capacity when the whole circulating traffic flow is in one circulating lane (the curve 100/0 in Fig. 3).

Right-lane and left-lane capacities at the major entries (A and $\mathrm{B}$ in Fig. 1), as well as the right-lane capacity at the minor entries ( $\mathrm{C}$ and D in Fig. 1) were calculated considering the circulating traffic flow only in the outer lane $\left(q_{c, \text { out }}\right)$ according to equation:

$C_{e}=\frac{3600}{t_{f}} \cdot\left(1-\frac{t_{\min } \cdot q_{c, \text { out }}}{3600}\right) \cdot e^{-\frac{q_{c, \text { out }}}{3600} \cdot\left(t_{c}-\frac{t_{f}}{2}-t_{\min }\right)}$

Notations in Equation 5.2 have the same meaning as in Equation 5.1. Values of the gap acceptance parameters are taken from the Slovak technical guidelines [10]:

left lane at minor entry: $\mathrm{t}_{\mathrm{c}}=3.9 \mathrm{~s}, \mathrm{t}_{\mathrm{f}}=2.7 \mathrm{~s}, \mathrm{t}_{\min }=2.1 \mathrm{~s}$;

right lane at minor and major entries: $\mathrm{t}_{\mathrm{c}}=4.0 \mathrm{~s}, \mathrm{t}_{\mathrm{f}}=2.8 \mathrm{~s}$, $\mathrm{t}_{\min }=2.1 \mathrm{~s}$;

left lane at major entry: $\mathrm{t}_{\mathrm{c}}=3.8 \mathrm{~s}, \mathrm{t}_{\mathrm{f}}=2.7 \mathrm{~s}, \mathrm{t}_{\min }=2.1 \mathrm{~s}$; 


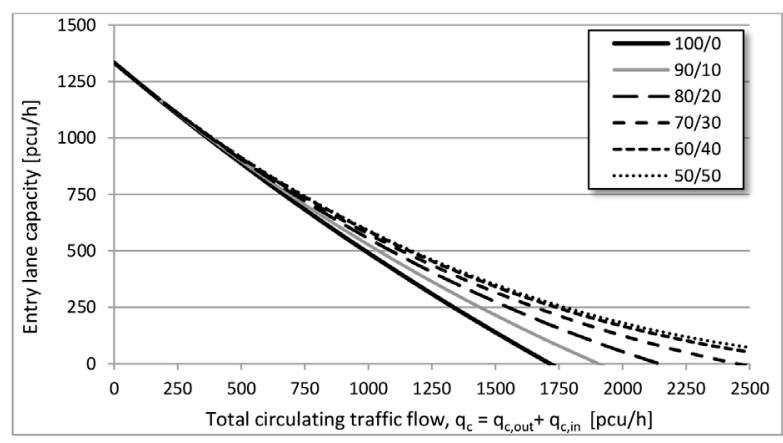

Fig. 3 Impact of the circulating traffic flow allocation on the entry lane capacity, Source: author

In the capacity model for the standard two-lane roundabout, only a total opposing circulating traffic flow in the two-lane circulatory carriageway $\left(q_{c}\right)$ without a traffic flow allocation is considered. It is because drivers are not strictly keeping in one circulating lane as in turbo-roundabouts, but there is an option to switch lanes at any point. Capacity of each entry lane (left-lane and right-lane capacity) is calculated using the formula:

$C_{e}=\frac{3600}{t_{f}} \cdot\left(1-\frac{t_{\min } \cdot q_{c}}{3600}\right) \cdot e^{-\frac{q_{c}}{3600} \cdot\left(t_{c}-\frac{t_{f}}{2}-t_{\min }\right)}$

Where $n_{c}$ is number of circulating lanes $\left(n_{c}=2\right)$ and other notations in Equation 5.3 have the same meaning as in Equation 5.1. Values of gap acceptance parameters are taken from the Slovak technical guidelines [11] and they are the same for left and right entry lanes: $\mathrm{t}_{\mathrm{c}}=3.9 \mathrm{~s}, \mathrm{t}_{\mathrm{f}}=2.7 \mathrm{~s}, \mathrm{t}_{\min }=2.1 \mathrm{~s}$.

\subsection{Entry traffic flows allocation procedure}

Allocation of traffic flows to right and left lanes at major entries and minor entries of the basic turbo-roundabout is entirely different because of its specific geometry. As it has been written, while through traffic can use both left and right lanes at major entries, only a left lane at minor entries can be used (right minor entry lane is determined just for a right-turning traffic, see Fig. 1).

As a result, the allocation procedure at the major entries on basic turbo-roundabouts (A and B in Fig. 1) is based on the assumption that drivers going straight will choose the entry lane with the lowest degree of saturation and thus with the lowest waiting time (or queue). Therefore, the through traffic proportion using the right lane at major entries under assumption of equilibrium state at peak hours (lanes have equal levels of saturation) in the capacity model is given by formula:

$p_{\text {major }}=\frac{C_{\text {major }, R} \cdot\left(q_{1}+q_{2}\right)-C_{\text {major }, L} \cdot q_{3}}{q_{2} \cdot\left(C_{\text {major }, L}+C_{\text {major }, R}\right)} ;$ where $q_{p}, q_{2}$ and $q_{3}$ are left, through and right traffic flows respectively and $C_{\text {major } R}$ and $C_{\text {maior } L}$ are right-lane and left-lane capacities at major entries calculated by the Equation 5.2. If $p_{\text {major }} \in(-\infty, 0) \Rightarrow p_{\text {major }}=0$ or $p_{\text {major }} \in(1, \infty) \Rightarrow p_{\text {major }}=1$.

Resulting traffic flows on right and left lanes at major entries $\left(q_{e, m a j o r: R}\right.$ and $\left.q_{e, \text { major: } L}\right)$ are then given by the Equations (5.5) and (5.6):

$q_{e, \text { major }, R}=p_{\text {major }} \cdot q_{2}+q_{3}$

$q_{e, \text { major }, L}=q_{1}+\left(1-p_{\text {major }}\right) \cdot q_{2}$

Because the right-turning traffic can use both left and right lanes at the minor entries on basic turbo-roundabouts ( $\mathrm{C}$ and $\mathrm{D}$ in Fig. 1), its proportion using the right lane is given by formula:

$p_{\text {minor }}=\frac{C_{\text {minor }, R} \cdot\left(q_{1}+q_{2}+q_{3}\right)}{q_{2} \cdot\left(C_{\text {minor }, L}+C_{\text {minor }, R}\right)} ; p_{\text {minor }} \in\langle 0,1\rangle$

where $C_{\text {minor } R}$ is the right-lane capacity at minor entries calculated by the Equation 5.2 and $C_{\text {maior } L}$ is the left-lane capacity at minor entries calculated by the Equation 5.1.

If $p_{\text {minor }} \in(-\infty, 0) \Rightarrow p_{\text {minor }}=0$ or $p_{\text {minor }} \in(1, \infty) \Rightarrow p_{\text {minor }}=1$.

Resulting traffic flows on right and left lanes at minor entries $\left(q_{e, \text { minor } R}\right.$ and $\left.q_{e, \text { minor } . L}\right)$ are given by the Equations (5.8) and (5.9):

$q_{e, \text { minor }, R}=p_{\text {minor }} \cdot q_{3}$

$q_{e, \text { minor }, L}=\left(q_{1}+q_{2}\right)+\left(1-p_{\text {minor }}\right) \cdot q_{3}$

Allocation of traffic flows to right and left lanes at all entries of the standard two-lane roundabout, in comparison to the basic turbo-roundabout, is quite different because of free-flow conditions at two-lane entries, circulatory carriageway and exits. This allows drivers to use any entry lane and subsequently any circulating lane. However, the use of the inner circulating lane in reality is not too much attractive for drivers, since there is dangerous crossing conflict point at the exit from this lane or there is the need of weaving (see Fig. 2). As a result, drivers do not utilise the left lane at two-lane entries sufficiently and the traffic flows in both lanes at the entry are not equally distributed. It has been observed not only on two-lane entries at the German roundabouts [12], but at the standard two-lane roundabouts in the Czech Republic and Slovakia. As it follows from surveys, the right lane is used more frequently than the left lane, about $70 \%$ of the total entry traffic flow during peak hours, even if there is a long queue [13 and 14]. This has a significant impact on the two-lane entry capacity, which is not as high in reality as was assumed according to the original Wu capacity model.

Since the two-lane entry capacity at standard two-lane roundabouts is strongly dependent on the allocation of traffic flows to left and right entries (see Fig. 4), it was also taken into 
account at the capacity calculations. Redistribution of traffic volumes to left and right entry lanes in the capacity model is assumed at a ratio of $30 \%: 70 \%$ (the curve $30 / 70$ in Fig. 4). The entry capacity with such a flows allocation is by $29 \%$ lower than for equal allocation (the curve 50/50 in Fig. 4).

The capacity of two-lane entry shown in Fig. 4 is dependent on flow rate of each entry lane and on the degree of saturation of the critical lane, and it is computed in accordance with the model described in more details, for example, in [1,15 and 16]

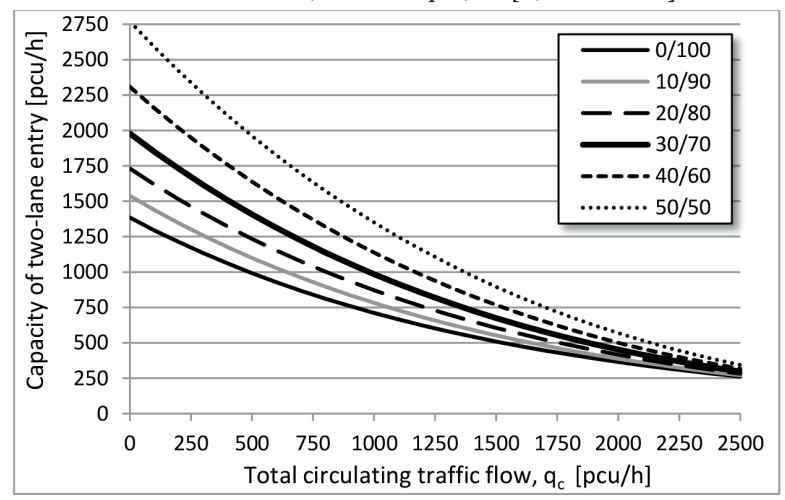

Fig. 4 Impact of the traffic flows allocation on the two-lane entry capacity; Source: Author

\subsection{Traffic conditions}

Since the proportion of traffic at major entries and proportion of left- and right-turning traffic have a significant influence on the intersection capacity, the following traffic conditions were modelled within capacity calculations:

Various ratios of the total traffic load at major entries and minor entries: Major/Minor from 100/0 to 50/50 (Major/ Minor $=90 / 10$ means that the total traffic load at the major entries $\mathrm{A}+\mathrm{B}$ is $90 \%$ and the total traffic load at the minor entries $\mathrm{C}+\mathrm{D}$ is $10 \%$ of the total roundabout traffic load),

- Various left-turning traffic proportion of the total entry traffic load $(\% \mathrm{~L})$ : from $0 \%$ to $100 \%$,

Various right-turning traffic proportion of the total entry traffic load (\%R): from $0 \%$ to $100 \%$.

The variations were modelled under symmetric demand at major entries, symmetric demand at minor entries and equal traffic split at all entries.

\subsection{Capacity performance of turbo-roundabouts}

The total traffic volume, as the sum of traffic volumes at all entries to the roundabout, at specified traffic conditions has been progressively increased from zero in $10 \mathrm{pcu} / \mathrm{h}$ steps until the degree of saturation of any minor or major entry lane of the turbo-roundabout and the two-lane roundabout reached the value 1.0 (the capacity reserve is zero).

The total capacity has been calculated for every possible combination of traffic conditions in $2.5 \%$ steps. In this paper, only selected important results which show a clear impact of different pattern of traffic load on the total capacity of basic turbo-roundabouts are presented in Fig. 5. The total capacity of basic turbo-roundabouts in comparison with the total capacity of two-lane roundabouts and also differences between the total capacities in percentages are shown in Fig. 6 (green colour means a higher capacity and red colour means a lower capacity of turboroundabouts).

As it can be seen from the results, the influence of the right-turning proportion $(\% \mathrm{R})$ on the total capacity of turboroundabouts significantly depends on the demand flows at major and minor entries (Major/Minor) - see slope of the curves on the left graphs in Fig. 5. When having the substantial prevalence of the major traffic flow over the minor traffic flow (see the graph Major/Minor $=90 / 10$ ) and the right-turning proportion is till 50\%, the influence is negligible. The difference in the total capacity is only about $1-4 \%$. However, at a higher proportion of rightturning traffic than $50 \%$, the total capacity goes down sharply (for example at the left-turning traffic proportion $\mathrm{L} 10 \%$, the total capacity reduction is up to $60 \%$ ). This is because only one lane (the right lane) at major entries for the right-turning traffic flow is determined and the lane becomes in terms of performance a critical lane.

The opposite situation occurs at a higher traffic load at minor entries, when increasing the right-turning traffic proportion up to $50 \%$, the total capacity increases significantly. The increase may be at the ratio of Major/Minor $=70 / 30$ approximately $15-50 \%$, and at balanced demand flows at all entries even up to $70 \%$ depending on the left-turning traffic proportion. At a higher proportion of right-turning traffic than $50 \%$, the total capacity is decreased, but not so sharply as at a high proportion of traffic load at major entries. For example, at balanced demand flows at all entries and at the left-turning traffic proportion $\mathrm{L} 10 \%$, the total capacity reduction is only $8 \%$.

A significant influence of the low right-turning traffic proportion on the total capacity is also illustrated on the right graphs in Fig. 5. At minor entries of turbo-roundabouts, the low proportion of right-turning traffic results to insufficient use of right lanes (determined only for the right-turning traffic flow) and a higher saturation of left lanes at the same time. At a lower proportion of right-turning traffic than $40 \%$, the total capacity of turbo-roundabouts thus can go down at increasing the minor traffic flow - see the breaking point in Fig. 5, right. The reason is the capacity failure of the left lane at minor entries.

The total capacity of turbo-roundabouts with increasing leftturning traffic proportion $(\% \mathrm{~L})$ gets always decreased (it can be up to $70 \%$ ) depending on demand flows at major and minor entries (Major/Minor) - see spacing of the curves in Fig. 5. When having 

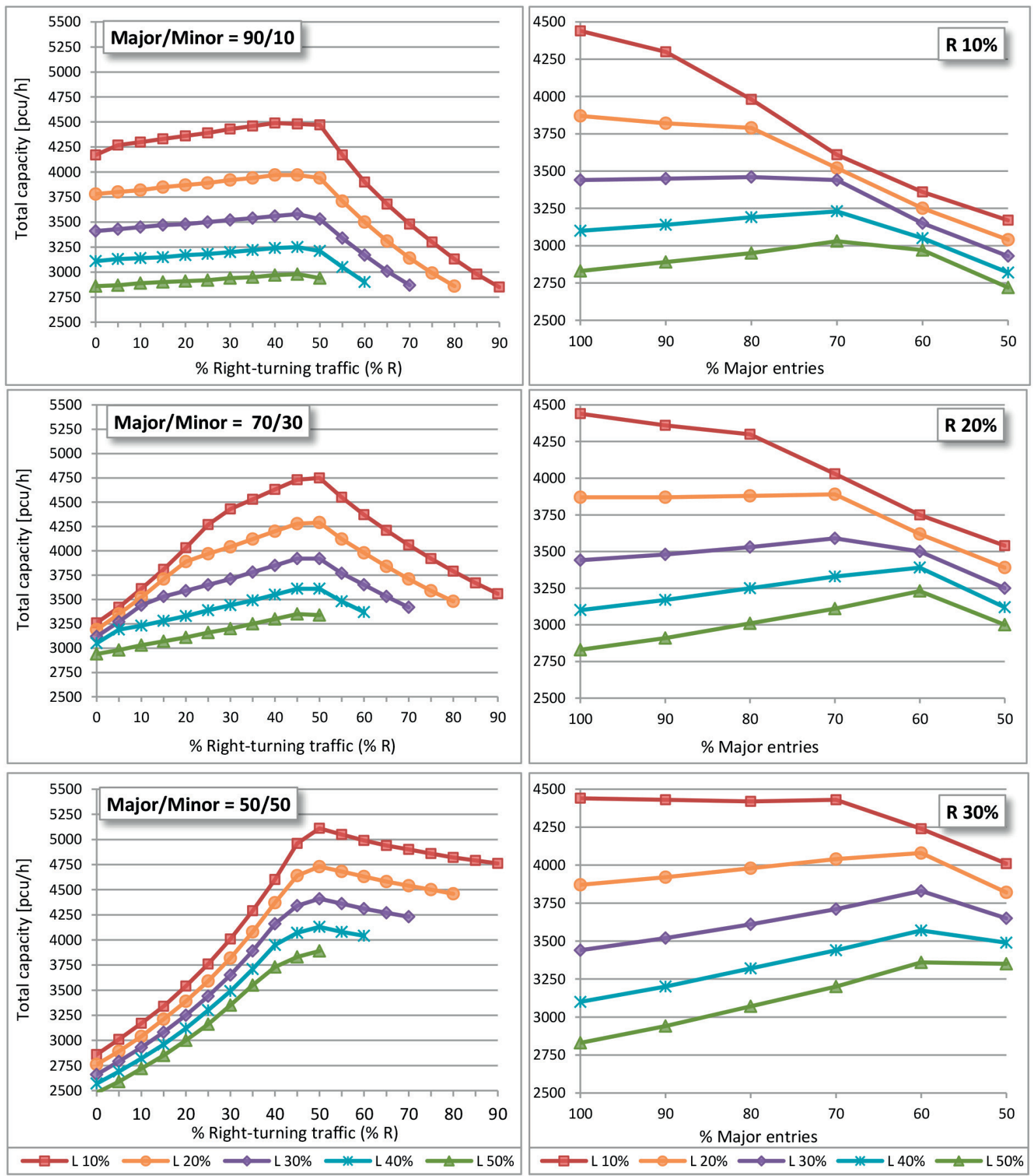

Fig. 5 Traffic condition influence on the total capacity of basic turbo-roundabouts; Source: Author

the substantial prevalence of the major traffic flow over the minor traffic flow (see the graph Major/Minor $=90 / 10$ ), the influence of the left-turning traffic proportion at the right-turning traffic proportion up to $50 \%$ is significant and subsequently decreases. On the contrary, at balanced demand flows at all entries, the influence of the left-turning traffic proportion at the right-turning traffic proportion up to $50 \%$ is low and subsequently increases.

Differences in geometry and also in efficiency of the use of both right and left entry lanes on compared roundabouts result to different total capacities at various traffic conditions (Fig. 6). At a substantial prevalence of the major traffic flow over the minor 


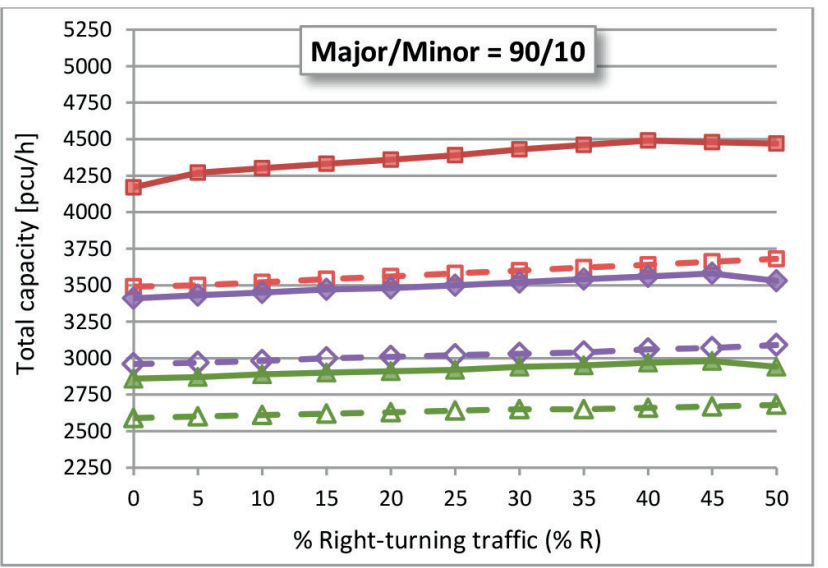

\begin{tabular}{|c|c|ccccccccccc|}
\hline \multicolumn{2}{|c|}{$90 / \mathbf{1 0}$} & \multicolumn{10}{|c|}{} \\
\cline { 2 - 12 } & $\mathbf{0}$ & $\mathbf{5}$ & $\mathbf{1 0}$ & $\mathbf{1 5}$ & $\mathbf{2 0}$ & $\mathbf{2 5}$ & $\mathbf{3 0}$ & $\mathbf{3 5}$ & $\mathbf{4 0}$ & $\mathbf{4 5}$ & $\mathbf{5 0}$ \\
\hline & $\mathbf{0}$ & $\mathbf{9}$ & 14 & 19 & 20 & 18 & 17 & 15 & 14 & 13 & 12 & 10 \\
& $\mathbf{5}$ & 14 & 20 & 22 & 20 & 18 & 17 & 15 & 14 & 13 & 12 & 10 \\
& $\mathbf{1 0}$ & 19 & 24 & 22 & 20 & 18 & 17 & 16 & 14 & 13 & 12 & 11 \\
& $\mathbf{1 5}$ & 24 & 24 & 22 & 20 & 19 & 17 & 16 & 14 & 13 & 12 & 11 \\
& $\mathbf{2 0}$ & 27 & 25 & 22 & 21 & 19 & 17 & 16 & 14 & 13 & 12 & 11 \\
$\mathbf{4} \mathbf{R}$ & $\mathbf{2 5}$ & 27 & 25 & 23 & 21 & 19 & 18 & 16 & 15 & 13 & 12 & 11 \\
& $\mathbf{3 0}$ & 28 & 25 & 23 & 21 & 19 & 18 & 16 & 15 & 13 & 12 & 11 \\
& $\mathbf{3 5}$ & 28 & 26 & 23 & 21 & 19 & 18 & 16 & 15 & 13 & 13 & 11 \\
& $\mathbf{4 0}$ & 28 & 26 & 23 & 21 & 19 & 18 & 16 & 15 & 14 & 13 & 12 \\
& $\mathbf{4 5}$ & 29 & 26 & 22 & 21 & 19 & 18 & 17 & 15 & 14 & 13 & 12 \\
& $\mathbf{5 0}$ & 27 & 24 & 21 & 20 & 18 & 16 & 14 & 13 & 12 & 11 & 10 \\
\hline
\end{tabular}

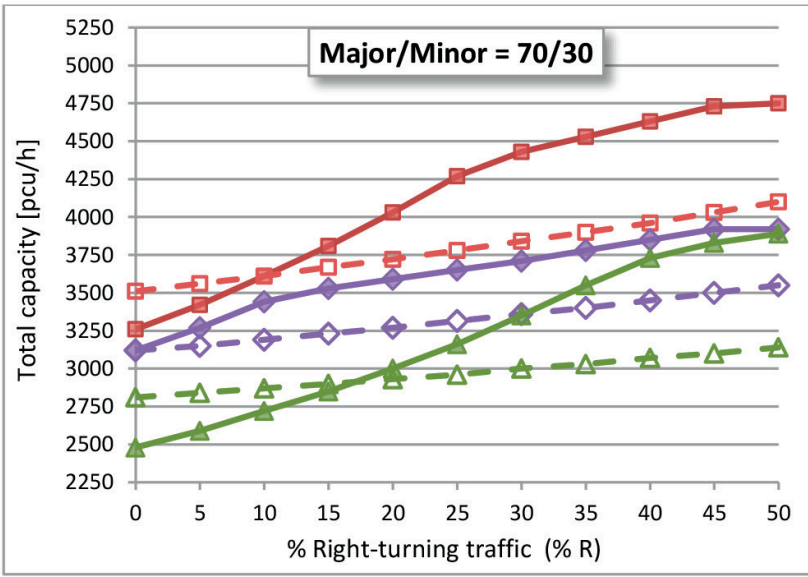

\begin{tabular}{|c|c|ccccccccccc|}
\hline \multicolumn{2}{|c|}{$70 / 30$} & \multicolumn{10}{|c|}{$\mathbf{3 0}$} & \multicolumn{10}{|c|}{} & $\mathbf{0}$ & $\mathbf{5}$ & $\mathbf{1 0}$ & $\mathbf{1 5}$ & $\mathbf{2 0}$ & $\mathbf{2 5}$ & $\mathbf{3 0}$ & $\mathbf{3 5}$ & $\mathbf{4 0}$ & $\mathbf{4 5}$ & $\mathbf{5 0}$ \\
\hline \multirow{4}{*}{} & $\mathbf{0}$ & -11 & -9 & -7 & -5 & -3 & -2 & 0 & 2 & 3 & 6 & 5 \\
& $\mathbf{5}$ & -8 & -6 & -4 & -2 & 0 & 2 & 4 & 6 & 7 & 6 & 5 \\
& $\mathbf{1 0}$ & -6 & -2 & 0 & 2 & 4 & 6 & 8 & 8 & 7 & 6 & 6 \\
& $\mathbf{1 5}$ & -3 & 2 & 4 & 6 & 8 & 10 & 9 & 8 & 7 & 6 & 6 \\
& $\mathbf{2 0}$ & 1 & 5 & 8 & 11 & 12 & 11 & 10 & 9 & 8 & 7 & 6 \\
$\% \mathbf{R}$ & $\mathbf{2 5}$ & 6 & 10 & 13 & 13 & 12 & 11 & 10 & 9 & 8 & 8 & 7 \\
& $\mathbf{3 0}$ & 10 & 15 & 15 & 14 & 13 & 12 & 10 & 10 & 9 & 8 & 7 \\
& $\mathbf{3 5}$ & 16 & 18 & 16 & 15 & 13 & 12 & 11 & 10 & 9 & 8 & 7 \\
& $\mathbf{4 0}$ & 20 & 18 & 17 & 15 & 14 & 13 & 12 & 10 & 10 & 9 & 7 \\
& $\mathbf{4 5}$ & 21 & 19 & 17 & 16 & 14 & 13 & 12 & 11 & 9 & 9 & 8 \\
& $\mathbf{5 0}$ & 19 & 17 & 16 & 14 & 13 & 11 & 10 & 10 & 8 & 7 & 6 \\
\hline
\end{tabular}
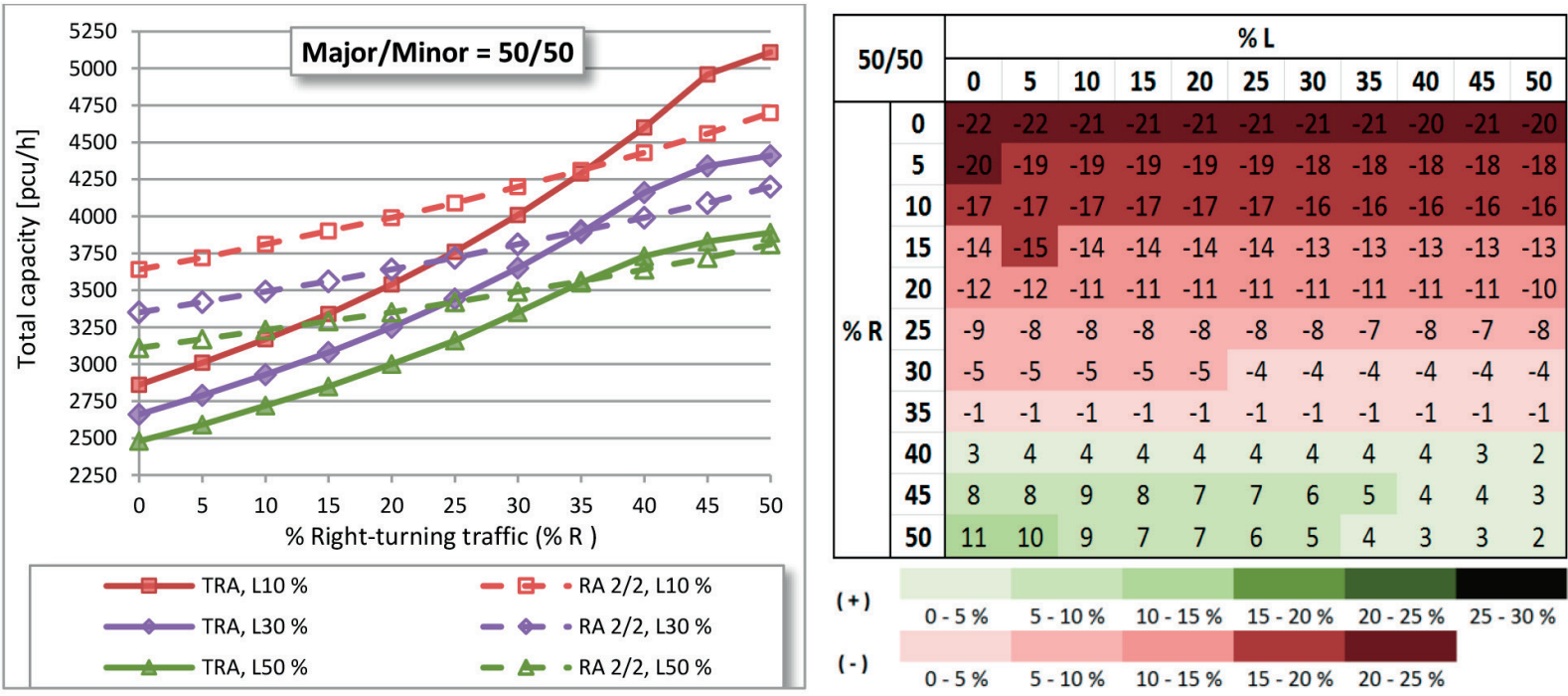

Fig. 6 Total capacity comparison: basic turbo-roundabouts (TRA) versus standard two-lane roundabouts (RA 2/2), Source: author

traffic flow (Major/Minor $=90 / 10)$, turbo-roundabouts have a higher total capacity than two-lane roundabouts. The reason is in more efficient uses of both lanes at major entries on turbo- roundabouts. In contrast, a low efficient use of left-entry lanes on two-lane roundabouts leads to a faster overloading of critical right-entry lanes. Of course, in an increasing left-turning traffic 
proportion over $70 \%$, the possibility of using both lanes at entries on two-lane roundabouts for the left-turning traffic flow leads to a higher total capacity compared to basic turbo-roundabouts, where left-turning drivers are forced to use only one lane (the left lane) at major entries. This applies even at other demand flows at major and minor entries.

At increased proportion of the traffic flow at minor entries, the total capacity of roundabouts significantly depends on the right-turning traffic proportion. If the proportion is too low $(\% \mathrm{R}=$ $10-20 \%$ ), the total capacity of turbo-roundabouts can be less than the total capacity of two-lane roundabouts. Even, under balanced traffic load at all entries and at the right-turning traffic proportion less than $30 \%$, the total capacity of turbo-roundabouts is always less than the total capacity of two-lane roundabouts. The reason is the right-entry lane at minor entries exclusively determined only for the right-turning traffic flow. At a low proportion of rightturning traffic, the entry lane is not used enough effectively and this leads to the capacity failure of the left entry lane, which has to ensure both through and left-turning movements.

\section{Conclusions}

The total capacity of turbo-roundabouts is, depending on traffic conditions, about 1.2 to 2.0 times higher than the capacity of single-lane roundabouts. Thanks to their specific geometry and ensuring the passage of vehicles through turbo-roundabouts with a significantly higher level of traffic safety, it can be achieved even from about $5 \%$ to $25 \%$ higher capacity in comparison to standard two-lane roundabouts. A higher performance of turbo-roundabouts can be achieved at a higher traffic load in dominant direction at major entries and lower traffic load at minor entries (more than about $70 \%$ proportion of the total traffic load at major entries). This is due to the more efficient use of both right and left lanes at major entries on turbo-roundabouts comparing to two-lane roundabouts, where only $30 \%$ proportion of the total entry traffic load on the left entry lane is expected. Furthermore, the total capacity of turbo-roundabouts is increased with an increasing proportion of right-turning traffic especially at minor entries (over $30 \%$ right-turning proportion).

On the other side, the total capacity of standard two-lane roundabouts can be about $5 \%$ to $20 \%$ higher in comparison to turbo-roundabouts. It is achievable at more balanced distribution of traffic loads on all roundabout entries and also at a higher proportion of left-turning traffic (more than $70 \%$ ).

It can be concluded that the turbo-roundabouts provide a combination of high level of traffic safety with a relatively large capacity. Through their indisputable advantages following the successful foreign experience, their more extensive use in Slovakia is expected in a short time. Subsequently it will be possible to test the real capacities of turbo-roundabouts, choose the appropriate capacity model together with input parameters and also set microsimulations to real Slovak conditions.

\section{Acknowledgement}

This contribution/publication is the result of the project implementation:

Centre of excellence for systems and services of intelligent transport, ITMS 26220120028 supported by the Research \& Development Operational Programme funded by the ERDF.
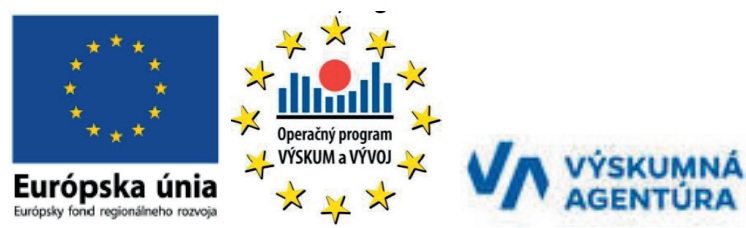

„Podporujeme výskumné aktivity na Slovensku/Projekt je spolufinancovaný zo zdrojov EÚ“

\section{References}

[1] MAURO, R., BRANCO, F.: Comparative Analysis of Compact Multilane Roundabouts and Turbo-Roundabouts. J. of Transportation Engineering 136, 316-322, 2010. ISSN 0733-947X.

[2] SILVA, A. B., SANTOS, S., GASPAR, M.: Turbo-roundabout Use and Design. CITTA $6^{\text {th }}$ Annual Conference on Planning Research, Responsive transports for smart mobility, 2013.

[3] VASCONCELOS, A. L. P., SILVA, A. B., SECO, A. J. D. M.: Capacity of Normal and Turbo-roundabouts: Comparative Analysis. Proc. of the Institution of Civil Engineers (ICE), 11/2012.

[4] TOLLAZZI, T., TURNSEK, S., RENCELJ, M.: Slovenian Experiences with Turbo-roundabouts. Proc. of the $3^{\text {rd }}$ Intern. Book on Roundabouts, TRB : USA, 2011.

[5] FORTUIJN, L. G. H.: Turbo Roundabouts: Design Principles and Safety Performance. J. of the Transportation Research Board, vol. 2096, pp. 16-24, 2009, ISBN 9780309126120.

[6] MAURO, R., CATTANI, M.: Potential Accident Rate of Turbo-Roundabouts. $4^{\text {th }}$ Intern. Symposium on Highway Geometric Design, Valencia, 2010. 
[7] FORTUIJN, L. G. H.: Turbo-Kreisverkehre - Entwicklungen und Erfahrungen. Seminar Aktuelle Theme der Strassenplanung. Bergisch Gladbach, 2007.

[8] BRILON, W., BONDZIO, L., WEISER, F.: Experiences with Turbo-Roundabouts in Germany. $5^{\text {th }}$ Rural Roads Design Meeting, Copenhagen. Available online at: http://nmfv.dk/wp-content/uploads/2014/04/Experiences-with-Turbo-Roundabouts-in-GermanyBrilonBondzio-Weiser.pdf, Accessed April 3-4, 2014.

[9] BRILON, S., WU, N., BONDZIO, L.: Unsignalized Intersections in Germany - A State of the Art 1997. Proc. of the Third International Symposium on Intersections without Traffic Signals, Portland: Oregon, 1997.

[10] TP 14/2015 Design of Turbo-roundabouts (in Slovak). Technical regulations. Ministry of Transport, Construction and Regional Development, Bratislava, 2015. Available online at: http://www.ssc.sk/files/documents/technicke-predpisy/tp2015/tp-14_2015.pdf.

[11] TP 16/2015 Roads Capacity Calculation (in Slovak). Technical regulations. Ministry of Transport, Construction and Regional Development, Bratislava, 2015. Available online at: http://www.ssc.sk/files/documents/technicke-predpisy/tp2015/tp-16_2015.pdf.

[12] BRILON, W.: Roundabouts: A State of the Art in Germany. National Roundabout Conference, Vail : Colorado, May 22-25, 2005.

[13] KOCIANOVA, A.: A New Approach to the Capacity Assessment of Two-Lane Entries on Roundabouts (in Slovak). Silnicni obzor 76, No. 7-8, 2015. ISSN 0322-7154.

[14] SMELY, M., RADIMSKY, M., APELTAUER, T.: Capacity of roundabouts with multi-lane entries (in Czech), Dopravni inzenyrstvi, 01/2011, ISSN 1801-8890.

[15] AKCELIK, R.: Roundabout Model Calibration Issue and a Case Study. TRB National roundabout conference: USA, 2005.

[16] GUERRIERI, M., CORRIERE, F., TICALI, D.: Turbo-Roundabouts: A Model to Evaluate Capacity, Delays, Queues and Level of Service. European J. of Scientific Research, vol. 92, No. 2, December, 2012, ISSN 1450-216X. 